\title{
Penerapan Metode Moora Dalam Evaluasi Kinerja Penyuluh Pertanian di UPT-BP Karang Dapo
}

\author{
Syafi'ul Hamidani*1 \\ ${ }^{1}$ Program Studi Sistem Informasi STMIK Bina Nusantara Jaya Lubuklinggau; \\ Jl. YosSudarso No.97 A 31621 \\ e-mail: *11 Hamidanipertama@gmail.com
}

\begin{abstract}
Abstrak
Kualitas sebuah dinas/ kantor akan meningkat seiring meningkatnya kinerja karyawan, banyak cara yang dapat dilakukan dinas/ kantor untuk meningkatkan kinerja karyawannya. UPT-BP(Unit Pelaksana teknis- Balai Pertanian ) kecamatan Karang Dapo adalah kantor balai pertanian yang menaungi para penyuluh pertanian di Kecamatan Karang Dapo kabupaten Musi Rawas Utara. Di UPT-BP Karang Dapo dari 9 Penyuluh pertanian telah dilakukan evaluasi kinerja dengan menggunakan 12 kriteria yang berasal dari permentan no 91 tahun 2013. Evaluasi kinerja dilakukan dengan teknik memutuskan alternatif serta kriteria yang hendak digunakan dengan metode MOORA, metode moora dipilih disebabkan cara ini sanggup menyaring alternatif terbaik disebabkan moora sanggup memastikan tujuan berdasarkan kriteria yang berlawanan. Penelitian ini menunjukkan bahwa salah satu penyuluh pertanian memiliki nilai palin tinggi dibandingkan dengan yang lain yaitu afriyansyah dengan nilai 13,098.
\end{abstract}

Kata kunci-Sistem Pendukung Keputusan, Moora, Penyuluh pertanian

\begin{abstract}
The quality of an office will increase along with the increase in employee performance, there are many ways that the office can improve the performance of its employees. The UPT-BP (Unit Pelaksana Teknis - Balai Pertanian) Karang Dapo sub-district is an agricultural office that covers agricultural counseling workers in Karang Dapo sub-district, Musi Rawas Utara district. At UPT-BP Karang Dapo from 9 agricultural counseling workers, performance evaluations have been carried out using 12 criteria derived from MOA 91/2013. filter out the best alternatives because moora is able to determine goals based on conflicting criteria. This research shows that one of the agricultural counseling agents has the highest value compared to the others, namely Afriyansyah with a value of 13.098 .
\end{abstract}

Keywords—Decision Support System, Moora, Agricultural counseling

\section{PENDAHULUAN}

$\mathrm{P}$ enyuluh pertanian lapangan merupakan salah satu jabatan fungsional dari dinas pertanian yang memiliki tugas pokok melaksanakan aktifitas persiapan penyuluhan pertanian, penerapan penyuluhan pertanian penilaian serta pelaporan, dan pengembangan penyuluhan pertanian [1], dalam pelaksanaannya kinerja dari penyuluh pertanian lapangan ini banyak mendapat tantangan dikarenakan berhadapan langsung dengan petani/ gabungan kelompok tani sehingga adakala kinerja dari penyuluh pertanian lapangan ini menjadi sedikit menurun. 
Penilaian kinerja yang baik adalah harapan semua pemangku kepentingan pada suatu instansi termasuk instansi pertanian, terkait penilaian kinerja seorang penyuluh dapat dilihat dari awal kegiatan yang dilakukan, mulai dari persiapan, pelaksanaan, evaluasi, dan pelaporan [2], Menurut informasi Kepala Unit Pelaksana Teknis Balai Pertanian (UPT-BP) Karang Dapo memiliki 9 orang penyuluh yang membina 8 desa/ 1 kelurahan dengan jumlah 113 kelompok tani binaan, selama ini pihak UPT-BP Karang Dapo dalam melakukan penilaian kinerja penyuluh pertanian hanya menggunakan check list untuk melaporkan setiap kriteria dari penyuluh pertanian setiap tahunnya, tentunya ini menunjukkan bahwa setiap penyuluh pertanian mempunyai beban dan tanggung jawab yang berbeda sehingga menimbulkan perbedaan hasil yang diperoleh petani/ gabungan kelompok tani dan juga pihak UPT-BP yang kesulitan dalam mengevaluasi dikarenakan belum adanya penghitungan yang pasti. Tujuan penelitian ini adalah untuk mengetahui kinerja penyuluh, sehingga diharapkan bisa menjadi tolak ukur bagi UPT-BP Karang Dapo kedepannya dalam mengevaluasi penyuluh pertanian.

Penelitian yang dilakukan oleh yogi primadasa dan alfiarini adalah membuat sistem pendukung keputusan penilaian kinerja karyawan menggunakan pembobotan ahp dan moora kasus pada penelitian ini merupakan selama ini lembaga dalam melaksanakan evaluasi kinerja karyawan masih memakai check list untuk mengecek attitude karyawan serta hanya bersumber pada kedisiplinan waktu [3].

Penelitian yang dilakukan oleh hengki juliansa yang berjudul data mining rough set dalam menganalisa kinerja dosen stmik bina nusantara jaya lubuklinggau adalah menerapkan data mining dengan metode rough set untuk menganalisa kinerja dosen berdasarkan pembelajaran, penelitian dan pengadian kepada masyarakat [4].

Penelitian yang dilakukan arie yandi saputra dan yogi primadasa yang berjudul penerapan metode moora dalam pemilihan sekolah dasar adalah melakukan penghitungan moora untuk pemilihan sd dengan kriteria; reputasi, tenaga pengajar, rasio guru serta siswa, jarak tempuh, sarana, serta saran keluarga sehingga menciptakan perangkingan nilai optimasi selaku tolak ukur [5].

Penelitian yang dilakukan oleh Triana Elizabet dan Tinaliah adalah Sistem Pendukung Keputusan Pemilihan Asisten Dosen Menggunakan Metode SAW yang bertujuan membantu pemilihan asisten dosen yang mana pada kasus sebelumnya asisten dosen hanya berdasarkan nilai "A" sehingga dirasa kurang efektif bagi mahasiswa atau adik adiknya [6]

Terakhir adalah penelitian yang dilakukan oleh Mohammad Guntur dan Robi Yanto adalah memberikan solusi untuk membantu membantu menyelesaikan masalah seleksi pemberian bantuan dana pengembangan usaha pangan masyarakat agar tepat sasaran menggunakan metode SMART [7]

\section{METODE PENELITIAN}

\subsection{Kajian Pustaka}

\subsubsection{Multi-Objective Optimization on The Basic of Ratio Analysis (MOORA)}

Metode Moora merupakan sistem yang memaksimalkan 2 ataupun lebih atribut yang saling berlawanan secara bertepatan [5], Langkah-langkah menggunakan metode MOORA adalah: [8]

1. membuat nilai matrik keputusan yang berdasarkan data alternatif dan kriteria

$$
X=\left[\begin{array}{lll}
x_{1.1} & x_{1.2} & x_{1 . n} \\
x_{2.1} & x_{2.2} & x_{2 . n} \\
x_{m .1} & x_{m .2} & x_{m . n}
\end{array}\right]
$$

Keterangan :

$\mathrm{x} \quad=$ matriks keputusan

x.n $\quad=$ nomor urut alternatif 
$\mathrm{x} . \mathrm{m}=$ nomor urut kriteria

2. melakukan normalisasi terhadap matrik $\mathrm{x}$

$$
X * i j=\frac{X i j}{\sqrt{\sum_{i=1}^{m} X i j^{2}}}
$$

Keterangan:

Xij : Respon alternatif $\mathrm{j}$ pada kriteria $\mathrm{i}$

$\mathrm{X} * \mathrm{ij}$ : Normalisasi $\mathrm{j}$ pada kriteria $\mathrm{i}$

3. normalisasi terbobot

Keterangan :

$$
W j * X i j
$$

Wj : Bobot Kriteria

Xij : Hasil Normalisasi alternatif j pada kriteria i.

4. menentukan hasil preferensi

$$
Y i=\sum_{j=1}^{g} w j * X i j-\sum_{j=g+1}^{n} w j * X i j
$$

Keterangan :

i : $1,2,3, \ldots \ldots$ g adalah atribut atau kriteria dengan status maksimal

$\mathrm{j}: \mathrm{g}+1, \mathrm{~g}+2, \mathrm{~g}+3, \ldots \ldots, \mathrm{n}$ adalah atribut atau kriteria dengan status minimal

$y * j$ : Matriks Normalisasi max-min alternatif $j$

\subsection{Metode Penelitian}

Kerangka pemikiran dari penelitian ini adalah seperti gambar 1 berikut ini :

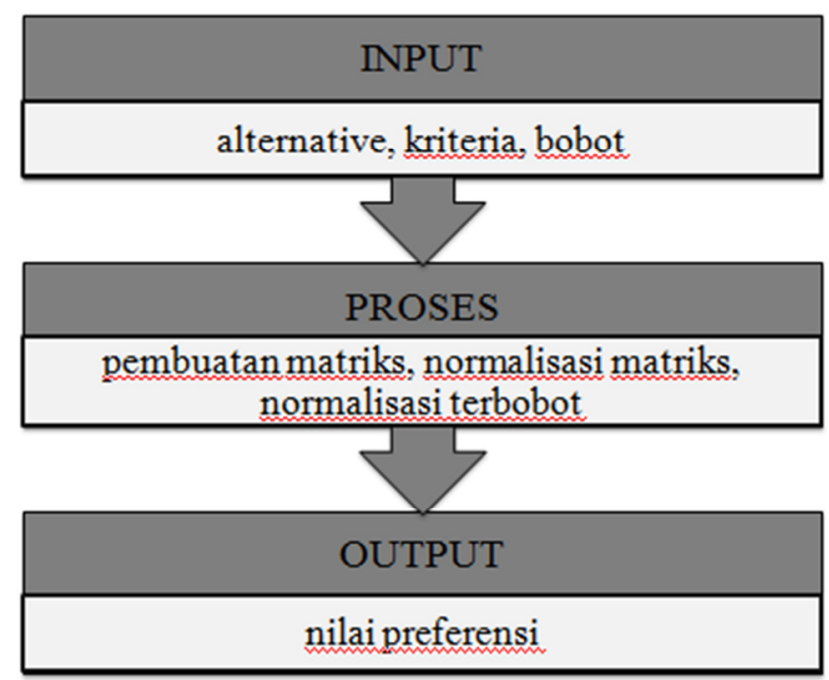

Gambar 1. Kerangka Berpikir

\subsubsection{Input (Alternative, Kriteria, Bobot)}

Tahapan pertama adalah memasukkan data alternatif, kriteria dan data bobot dimana data alternatif didapatkan bersumber pada data penyuluh pertanian di UPT-BP Karang Dapo,data kriteria didapatkan didapatkan dari peraturan menteri pertanian [9] sedangkan bobotnya didapatkan dari pedoman penilaian Penyuluh Pertanian Lapangan Teladan [10] 


\subsubsection{Proses}

Tahapan selanjututnya adalah tahapan pada metode MOORA yaitu pembuatan matrik, normalisasi matriks, dan normalisasi terbobot

\subsubsection{Output (Nilai Preferensi)}

Output yang didapatkan adalah nilai preferensi yg dapat digunakan sebagai acuan hasil dari penelitian ini

\section{HASIL DAN PEMBAHASAN}

Pemilihan data kriteria dan bobot adalah proses awal dari penelitian ini, adapun data kriteria dan bobotnya adalah seperti pada tabel 1 berikut ini,

Tabel 1, Kriteria dan Bobot Penelitian

\begin{tabular}{|c|l|c|}
\hline Simbol & \multicolumn{1}{|c|}{ Kriteria } & Bobot \\
\hline Kr1 & Membuat data potensi wilayah dan agro ekosistem & 1,2 \\
\hline Kr2 & $\begin{array}{l}\text { Memberikan pengajaran Penyusunan Rencana Definitif Kebutuhan } \\
\text { Kelompok (RDKK) }\end{array}$ & 1,2 \\
\hline Kr3 & Membuat programa penyuluhan pertanian & 5 \\
\hline Kr4 & Membuat Rencana Kerja Tahunan Penyuluhan Pertanian (RKTPP) & 1,2 \\
\hline Kr5 & Melakukan desiminasi/penyebaran bahan penyuluhan kepada petani & 5 \\
\hline Kr6 & Melakukan kunjungan tatap muka perorangan/ kelompok & 2,5 \\
\hline Kr7 & Melakukan demonstrasi cara dan hasil & 1,2 \\
\hline Kr8 & $\begin{array}{l}\text { Melakukan temu-temu (temu lapang, temu wicara, temu teknis, temu } \\
\text { karya, temu usaha) }\end{array}$ & 1,2 \\
\hline Kr9 & Melakukan kursus/ Penyuluhan & 1,2 \\
\hline Kr10 & Melakukan penambahan kapasitas petani terhadap akses informasi & 1,2 \\
\hline Kr11 & $\begin{array}{l}\text { Melakukan bimbingan kepada penyuluh pertanian untuk Menumbuhkan } \\
\text { dan mengembangkan kelompok tani }\end{array}$ & 2,5 \\
\hline Kr12 & $\begin{array}{l}\text { Melakukan bimbingan kepada penyuluh pertanian untuk menumbuhkan } \\
\text { dan mengembangkan kelembagaan ekonomi petani }\end{array}$ & 1,2 \\
\hline Kr13 & $\begin{array}{l}\text { Melakukan bimbingan teknis dalam mengembangkan produksi komoditi } \\
\text { unggulan }\end{array}$ & 3,5 \\
\hline Kr14 & Melakukan evaluasi pelaksanaan penyuluh pertanian & 1,2 \\
\hline Kr15 & Melakukan evaluasi dampak penyuluhan pertanian & 1,2 \\
\hline Kr16 & Membuat laporan pelaksanaan penyuluhaan pertanian & 2,5 \\
\hline
\end{tabular}

Pelaksanaan metode Moora dalam penilaian memakai 16 kriteria yang diajukan dalam pengambilan keputusan berdasarkan pada Peraturan Menteri Pertanian [9] sedangkan untuk bobotnya berdasarkan pedoman penilaian Penyuluh Pertanian Lapangan Teladan [10] selanjutnya untuk kriteria pada tabel 1 dibuat bobotnya seperti pada tabel 2 berikut ini : 
Tabel 2, Bobot Penelitian

\begin{tabular}{|c|c|}
\hline Nilai & Bobot \\
\hline Sangat Baik & 5 \\
\hline Baik & 4 \\
\hline Cukup & 3 \\
\hline Jelek & 2 \\
\hline Sangat Jelek & 1 \\
\hline
\end{tabular}

Penelitian ini memakai 9 penyuluh pertanian lapangan sebagai alternatif dan sebagai percontohan untuk dievaluasi kinerjanya yang bersumber pada kriteria Permentan 2013. 9 sampel penyuluh tersebut adalah seperti pada Tabel 3 berikut ini.

Tabel 3, Alternatif Penelitan

\begin{tabular}{|c|l|}
\hline Inisial & Nama Penyuluh Pertanian \\
\hline SW & Saprika Wariha, SP \\
\hline AF & Afriyasyah \\
\hline RP & Ratih Purwasih, S.Hut \\
\hline MK & Medi Kasmara, SP \\
\hline RF & Riza Fahlevi, SP \\
\hline DS & Doni Surahman, SP \\
\hline SR & Saroitika \\
\hline BS & Bram Sandi, SP \\
\hline AI & Ali Imron \\
\hline
\end{tabular}

Langkah berikutnya ialah melaksanakan evaluasi kinerja penyuluh pertanian berlandaskan instrumen evaluasi kinerja penyuluh pertanian UPT- BP Karang Dapo berlandaskan instrumen yang sudah diisi oleh Tim Penilai Evaluasi Kinerja di UPT- BP Karang Dapo melaksanakan analisa metode MOORA. Data seperti table 4 berikut:

Tabel 4, Data Bobot Alternatif Penelitian

\begin{tabular}{|l|r|r|r|r|r|r|r|r|r|}
\hline \multirow{2}{*}{ Kriteria } & \multicolumn{7}{|c|}{ Alternatif (Penyuluh Pertanian) } \\
\cline { 2 - 10 } & sw & Af & rp & Mk & rf & ds & sr & Bs & ai \\
\hline Kr1 & 1 & 2 & 1 & 1 & 1 & 1 & 1 & 1 & 1 \\
\hline Kr2 & 1 & 3 & 2 & 2 & 2 & 2 & 2 & 1 & 1 \\
\hline Kr3 & 2 & 3 & 1 & 2 & 1 & 2 & 3 & 1 & 1 \\
\hline Kr4 & 2 & 1 & 1 & 1 & 1 & 1 & 1 & 1 & 1 \\
\hline $\mathrm{Kr} 5$ & 1 & 2 & 3 & 1 & 3 & 1 & 1 & 1 & 1 \\
\hline $\mathrm{Kr} 6$ & 5 & 5 & 5 & 5 & 5 & 5 & 5 & 5 & 5 \\
\hline $\mathrm{Kr} 7$ & 1 & 2 & 1 & 1 & 1 & 1 & 1 & 2 & 1 \\
\hline $\mathrm{Kr} 8$ & 1 & 1 & 1 & 2 & 3 & 1 & 1 & 3 & 1 \\
\hline $\mathrm{Kr} 9$ & 2 & 3 & 1 & 3 & 1 & 4 & 1 & 3 & 2 \\
\hline $\mathrm{Kr} 10$ & 3 & 3 & 3 & 2 & 3 & 2 & 2 & 2 & 3 \\
\hline $\mathrm{Kr} 11$ & 1 & 3 & 3 & 1 & 1 & 1 & 1 & 1 & 1 \\
\hline $\mathrm{Kr} 12$ & 1 & 3 & 3 & 2 & 3 & 1 & 1 & 1 & 1 \\
\hline
\end{tabular}




\begin{tabular}{|l|l|l|l|l|l|l|l|l|l|}
\hline Kr13 & 1 & 3 & 3 & 1 & 1 & 1 & 1 & 2 & 3 \\
\hline Kr14 & 4 & 3 & 3 & 3 & 1 & 1 & 1 & 2 & 3 \\
\hline Kr15 & 2 & 3 & 3 & 2 & 1 & 2 & 3 & 1 & 1 \\
\hline Kr16 & 2 & 3 & 3 & 2 & 1 & 1 & 1 & 2 & 1 \\
\hline
\end{tabular}

Setelah didapat data diatas langkah selanjutnya adalah membuat matrik dengan menggunakan persamaan (1)

$$
X=\left[\begin{array}{ccccccccc}
1 & 2 & 1 & 1 & 1 & 1 & 1 & 1 & 1 \\
1 & 3 & 2 & 2 & 2 & 2 & 2 & 1 & 1 \\
. . & . . & .3 & . & . & \cdots & . . & . & . . \\
2 & 3 & 3 & 2 & 1 & 2 & 3 & 1 & 1 \\
2 & 3 & 3 & 2 & 1 & 1 & 1 & 2 & 1
\end{array}\right]
$$

Setelah persamaan (1) selanjutnya dilakukan normalisasi dengan melakukan penghitungan secara detail pada data pertama menggunakan persamaan (2).

$$
\begin{aligned}
& x_{1.1}=\frac{x_{1.1}}{\sqrt{\left(x 1.1^{2}+x 2.1^{2}+x 3.1^{2}+x 4.1^{2}+x 5.1^{2}+x 6.1^{2}+x 7.1^{2}+x 8.1^{2}+x 9.1^{2}\right)}} \\
& x_{1.1}=\frac{1}{\sqrt{\left(1^{2}+2^{2}+1^{2}+1^{2}+1^{2}+1^{2}+1^{2}+1^{2}+1^{2}\right)}} \\
& x_{1.1}=\frac{1}{\sqrt{(1+4+1+1+1+1+1+1+1)}} \\
& x_{1.1}=\frac{1}{\sqrt{12}} \\
& x_{1.1}=\frac{1}{3,46} \\
& x_{1.1}=0,288
\end{aligned}
$$

Lakukan perhitungan diatas untuk setiap kriteria dan alternatif, sehingga didapatlah hasil keseluruhan normalisasi seperti pada tabel 5 berikut:

Tabel 5, Normalisasi Data

\begin{tabular}{|l|c|c|c|c|c|c|c|c|c|}
\hline \multirow{2}{*}{ Kriteria } & \multicolumn{8}{|c|}{ Alternatif (Penyuluh Pertanian) } \\
\cline { 2 - 10 } & sw & Af & rp & Mk & rf & Ds & sr & bs & ai \\
\hline Kr1 & 0,289 & 0,577 & 0,289 & 0,289 & 0,289 & 0,289 & 0,289 & 0,289 & 0,289 \\
\hline Kr2 & 0,167 & 0,500 & 0,333 & 0,333 & 0,333 & 0,333 & 0,333 & 0,167 & 0,167 \\
\hline Kr3 & 0,343 & 0,514 & 0,171 & 0,343 & 0,171 & 0,343 & 0,514 & 0,171 & 0,171 \\
\hline Kr4 & 0,577 & 0,289 & 0,289 & 0,289 & 0,289 & 0,289 & 0,289 & 0,289 & 0,289 \\
\hline Kr5 & 0,147 & 0,295 & 0,442 & 0,147 & 0,442 & 0,147 & 0,147 & 0,147 & 0,147 \\
\hline Kr6 & 0,277 & 0,277 & 0,277 & 0,277 & 0,277 & 0,277 & 0,277 & 0,277 & 0,277 \\
\hline Kr7 & 0,258 & 0,516 & 0,258 & 0,258 & 0,258 & 0,258 & 0,258 & 0,516 & 0,258 \\
\hline Kr8 & 0,189 & 0,189 & 0,189 & 0,378 & 0,567 & 0,189 & 0,189 & 0,567 & 0,189 \\
\hline Kr9 & 0,272 & 0,408 & 0,136 & 0,408 & 0,136 & 0,544 & 0,136 & 0,408 & 0,272 \\
\hline Kr10 & 0,338 & 0,338 & 0,338 & 0,225 & 0,338 & 0,225 & 0,225 & 0,225 & 0,338 \\
\hline Kr11 & 0,152 & 0,457 & 0,457 & 0,152 & 0,152 & 0,152 & 0,152 & 0,152 & 0,152 \\
\hline Kr12 & 0,136 & 0,408 & 0,408 & 0,272 & 0,408 & 0,136 & 0,136 & 0,136 & 0,136 \\
\hline Kr13 & 0,136 & 0,408 & 0,408 & 0,136 & 0,136 & 0,136 & 0,136 & 0,272 & 0,408 \\
\hline
\end{tabular}

Hamidani, [Penerapan Metode Moora Dalam Evaluasi Kinerja Penyuluh Pertanian di UPT-BP Karang] Dapo 
Jatisi

ISSN 2407-4322

Vol. 8, No. 4, Desember 2021, Hal. 2010-2018

E- ISSN 2503-2933

2016

\begin{tabular}{|l|l|l|l|l|l|l|l|l|l|}
\hline Kr14 & 0,456 & 0,342 & 0,342 & 0,342 & 0,114 & 0,114 & 0,114 & 0,228 & 0,342 \\
\hline Kr15 & 0,258 & 0,387 & 0,387 & 0,258 & 0,129 & 0,258 & 0,387 & 0,129 & 0,129 \\
\hline Kr16 & 0,277 & 0,416 & 0,416 & 0,277 & 0,139 & 0,139 & 0,139 & 0,277 & 0,139 \\
\hline
\end{tabular}

Setelah nilai normalisasi didapatkan, selanjutnya adalah menghitung normalisasi terbobot menggunakan persamaan (3)

$x_{1.1}=x_{1.1} *$ bobot

$x_{1.1}=0,289 * 1,2$

$x_{1.1}=0,346$

Lakukan perhitungan diatas untuk setiap kriteria dan alternatif, sehingga didapatlah hasil keseluruhan normalisasi seperti pada tabel 6 berikut :

Tabel 6, Normalisasi Terbobot

\begin{tabular}{|l|c|c|c|c|c|c|c|c|c|}
\hline \multirow{2}{*}{ Kriteria } & \multicolumn{8}{|c|}{ Alternatif (Penyuluh Pertanian) } \\
\cline { 2 - 11 } & sw & Af & rp & Mk & Rf & Ds & sr & bs & ai \\
\hline Kr1 & 0,346 & 0,693 & 0,346 & 0,346 & 0,346 & 0,346 & 0,346 & 0,346 & 0,346 \\
\hline Kr2 & 0,200 & 0,600 & 0,400 & 0,400 & 0,400 & 0,400 & 0,400 & 0,200 & 0,200 \\
\hline Kr3 & 1,715 & 2,572 & 0,857 & 1,715 & 0,857 & 1,715 & 2,572 & 0,857 & 0,857 \\
\hline Kr4 & 0,693 & 0,346 & 0,346 & 0,346 & 0,346 & 0,346 & 0,346 & 0,346 & 0,346 \\
\hline Kr5 & 0,737 & 1,474 & 2,212 & 0,737 & 2,212 & 0,737 & 0,737 & 0,737 & 0,737 \\
\hline Kr6 & 0,693 & 0,693 & 0,693 & 0,693 & 0,693 & 0,693 & 0,693 & 0,693 & 0,693 \\
\hline Kr7 & 0,310 & 0,620 & 0,310 & 0,310 & 0,310 & 0,310 & 0,310 & 0,620 & 0,310 \\
\hline Kr8 & 0,227 & 0,227 & 0,227 & 0,454 & 0,680 & 0,227 & 0,227 & 0,680 & 0,227 \\
\hline Kr9 & 0,327 & 0,490 & 0,163 & 0,490 & 0,163 & 0,653 & 0,163 & 0,490 & 0,327 \\
\hline Kr10 & 0,405 & 0,405 & 0,405 & 0,270 & 0,405 & 0,270 & 0,270 & 0,270 & 0,405 \\
\hline Kr11 & 0,381 & 1,144 & 1,144 & 0,381 & 0,381 & 0,381 & 0,381 & 0,381 & 0,381 \\
\hline Kr12 & 0,163 & 0,490 & 0,490 & 0,327 & 0,490 & 0,163 & 0,163 & 0,163 & 0,163 \\
\hline Kr13 & 0,476 & 1,429 & 1,429 & 0,476 & 0,476 & 0,476 & 0,476 & 0,953 & 1,429 \\
\hline Kr14 & 0,547 & 0,410 & 0,410 & 0,410 & 0,137 & 0,137 & 0,137 & 0,274 & 0,410 \\
\hline Kr15 & 0,310 & 0,465 & 0,465 & 0,310 & 0,155 & 0,310 & 0,465 & 0,155 & 0,155 \\
\hline Kr16 & 0,693 & 1,040 & 1,040 & 0,693 & 0,347 & 0,347 & 0,347 & 0,693 & 0,347 \\
\hline
\end{tabular}

Langkah selanjutnya menghitung nilai optimasi keseluruhan dengan menggunakan persamaan (4).

$X_{1.1}=\quad 0,346+0,200+1,715+0,693+0,737+0,693+0,310+0,227+0,327+0,405+$

$X_{1.1}=8,224$

Berikut Hasil optimasi untuk keseluruhan penyuluh adalah pada table 7 berikut:

Hamidani, [Penerapan Metode Moora Dalam Evaluasi Kinerja Penyuluh Pertanian di UPT-BP Karang] Dapo 
Tabel 7, Hasil Optimasi

\begin{tabular}{|l|l|}
\hline Alternatif/ Nama Penyuluh Pertanian & Nilai optimasi \\
\hline Saprika Wariha, SP & 8,224 \\
\hline Afriyansyah & 13,098 \\
\hline Ratih Purwasih, S.Hut & 10,938 \\
\hline Medi Kasmara, SP & 8,359 \\
\hline Riza Fahlevi, SP & 8,400 \\
\hline Doni Surahman, SP & 7,512 \\
\hline Saroitika & 8,035 \\
\hline Bram Sandi, SP & 7,860 \\
\hline Ali Imron & 7,334 \\
\hline
\end{tabular}

dilakukan dengan persamaan secara kualitatif maupun kuantitatif.Hasil percobaan sebaiknya ditampilkan dalam berupa grafik atau pun tabel. Untuk grafik dapat mengikuti format untuk diagram dan gambar.

\section{KESIMPULAN}

Dilihat dari penelitian dapat disimpulkan bahwa metode moora dapat digunakan dalam mengevaluasi kinerja penyuluh pertanian dikarenakan moora mampu menentukan nilai bobot dari setiap atribut sehingga dapat menyeleksi alternatif terbaik, selain itu berdasarkan perhitungan metode MOORA dapat ditarik kesimpulan bahwa penyuluh pertanian yg memiliki kinerja paling baik di UPT-BP Karang Dapo adalah afriyansyah dengan nilai bobot 13,098 diikuti oleh ratih purwasih

\section{SARAN}

Untuk pengembangan penelitian selanjutnya peneliti dapat melakukan perbandingan metode dengan metode lainnya seperti metode Analytical Hierarchy Process (AHP) dan metode Simple Additive Weighting (SAW).

\section{UCAPAN TERIMA KASIH}

Ucapan terima kasih kami sampaikan kepada Kepala UPT-BP Karang Dapo (Bapak Sola Sohar, SP) dan seluruh staf, serta Lembaga Penelitian dan Pengabdian kepada Masyarakat STMIK Bina Nusantara Jaya Lubuklinggau.

\section{DAFTAR PUSTAKA}

[1] M. N. P. A. Negara, February 2008. [Online]. Available: http://hukum.unsrat.ac.id/men/menpan2008_2.pdf.

[2] D. Suranti, 2013, "Penerapan Metode Promethee Dalam Evaluasi Kinerja Penyuluh Pertanian pada Unit Pelaksana Teknis Balai Penyuluh Pertanian," Register: Jurnal Ilmiah Teknologi Sistem Informasi, Vol. 5, No. 1, pp. 13-23, Agustus 2019. 
[3] Y. Primadasa and Alfiarini, 2019, "Sistem Pendukung Keputusan Penilaian Kinerja Karyawan Menggunakan Pembobotan Ahp dan Moora," Cogito Smart Journal, Vol. 5, No. 2, pp. 159-170, Desember 2019.

[4] H. Juliansa, 2019, "Data Mining Rough Set Dalam Menganalisa Kinerja Dosen STMIK Bina Nusantara Jaya Lubuklinggau," JUSIM (Jurnal Sistem Informasi Musirawas), Vol. 4, No. 1, pp. 11-17, Juni 2019.

[5] Y. S. Arie and Y. Primadasa, 2019, "Penerapan Metode Moora Dalam Pemilihan Sekolah Dasar," SISTEMASI: Jurnal Sistem Informas, Vol. 8, No. 2, p. 305 -312, Mei 2019.

[6] T. Elizabeth and T. 2020, "Sistem Pendukung Keputusan Pemilihan Asisten Dosen Menggunakan Metode SAW," Jurnal Teknik Informatika dan Sistem Informasi, pp. 71-80, 2020.

[7] M. Guntur and R. Yanto, 2019, "Penerapan Metode SMART untuk Seleksi Kelayakan Penerima Bantuan Pengembangan Usaha Pangan Masyarakat," Telematika, Vol. 12, No. 2, pp. 149 - 159, Agustus 2019.

[8] Y. Sa'adati, S. Fadli and K. Imtihan, 2018, "Analisis Penggunaan Metode AHP dan MOORA Untuk Menentukan Guru Berprestasi Sebagai Ajang Promosi Jabatan," Sinkron: Jurnal \& Penelitian Teknik Informatika, Vol. 3, No. 1, pp. 82-90, Oktober 2018 .

[9] M. PERTANIAN, September 2013. [Online]. Available:

https://peraturan.bkpm.go.id/jdih/userfiles/batang/Permentan_91_2013.pdf.

[10] M. PERTANIAN, Maret 2011. [Online]. Available: http://bppsdmp.pertanian.go.id/storage/app/media/KIP/Regulasi/ Permentan\%20No.14\%20Tahun\%202011\%20(pedoman\%20penilaian\%20penyuluh $\% 20$ pertanian\%20swadaya\%20teladan)/Permentan\%20No.14\%20Tahun\%202011\%20(fi x).pdf. 